\title{
Effects of boundary conditions on foot behaviour in the standing position in 3D finite element foot model
}

\author{
Shane Johnson*, Haihua Ou \\ From 4th Congress of the International Foot and Ankle Biomechanics (i-FAB) Community \\ Busan, Korea. 8-11 April 2014
}

\section{Introduction}

The most common physical injuries are injuries of the lower extremity. In fact, controlled studies on highly physically active groups such as athletes and military personnel show that five injury types are repeatedly cited as accounting for over 50 percent of all training injuries: stress fractures, overuse injuries of the knee, Plantar Fasciitis, Achilles Tendonitis, and ankle sprains [1-5].

Three-dimensional finite element analysis (3D FEA) of the foot in the standing position allows researchers to analyze the relationship between foot behavior and orthotic designs, which may help to relieve or prevent such injuries. Various 3D FEA models of the foot in the standing position show very different boundary conditions, including: fixing the fibula and tibia at different points between the ankle and knee, fixing the talus, and applying slip/no-slip conditions in the articular surfaces [6-12]. This may have a large effect on overall foot stiffness and the strain of the Plantar Aponeurosis.

This study is developed to investigate the influence of these boundary conditions on the overall foot stiffness and strain in the Plantar Aponeurosis in the standing position.

\section{Method}

A parametric study was conducted by varying the boundary conditions on a 3D FEA foot model by:

1. Varying slip/no slip conditions at the articular surfaces (Tibia/Talus, Fibula/Talus, Talus/Calcaneous, Talus/ Navicular, Calcaneous/Cuboid);

2. Fixing/Pinning different points between the proximal and distal ends of the tibia and fibula;

\footnotetext{
* Correspondence: shane.johnson@sjtu.edu.cn

University of Michigan and Shanghai Jiao Tong University Joint Institute,
} Shanghai, 200240, China magnitudes;

The strain of the Plantar Aponeurosis and plantar pressures under different boundary conditions are compared with experimental results found in the literature $[13,14]$.

\section{Results}

The result shows that changing boundary conditions has a large effect on the overall foot stiffness and strain in the Plantar Aponeurosis.

This analysis provides researchers conducting $3 \mathrm{D}$ finite element analysis on the foot with a guide on which parameters, especially the force-displacement boundary conditions, have the largest effect on particular foot behaviors. This is critical in later analyzing the interaction between the foot and new orthotic designs.

Published: 8 April 2014

References

Gardner LI, Dziados JE, Jones BH, Brundage JF, Harris JM, Sullivan R, Gill P.

Prevention of lower extremity stress fractures: a controlled trial of a shock absorbent insole. Am J Public Health 1988, 78:1563-1567.

2. Jones BH: Overuse injuries of the lower extremities associated with marching, jogging, and running: a review. Mil Med 1983, 148:783-787.

3. Jones BH, Knapik JJ: Physical training and exercise-related injuries. Surveillance, research and injury prevention in military populations. Sports Med 1999, 27:111-125.

4. Kowal DM: Nature and causes of injuries in women resulting from an endurance training program. Am J Sports Med 1980, 8:265-269.

5. Reinker KA, Ozburne S: A comparison of male and female orthopaedic pathology in basic training. Mil Med 1979, 144:532-536.

6. Liu Q-H, Yu B, JIN D, Zhang M-C, Hu Y-J, Wang D, Luo J-W: Construction of a finite element

. Chen W-P, Tang F-T, Ju C-W: Stress distribution of the foot during midstance to push-off in barefoot gait: a 3-D finite element analysis. Clin Biomech 2001, 16:614-620. 
8. Bandak FA, Tannous RE, Toridis T: On the development of an osseoligamentous finite element model of the human ankle joint. Int J Solids Struct 2001, 38:1681-1697.

9. Gefen $\mathrm{A}$ : Stress analysis of the standing foot following surgical plantar fascia release. J Biomech 2002, 35:629-637.

10. Tao K, Wang D, Wang C, Wang X, Liu A, Nester CJ, Howard D: An In Vivo Experimental Validation of a Computational Model of Human Foot. J Bionic Eng 2009, 6:387-397.

11. Chueng JT-M, Zhang M: A 3-Dimensional Finite Element Model of the Human Foot and Ankle for Insole Design. Arch Phys Med Rehabil 2005, 86:353-360.

12. Antunes PJ, Dias GR, Coelho AT, Rebelo F, Pereira T: Non-Linear Finite Element Modelling of Anatomically Detailed 3D Foot Model. 2008.

13. Kogler GF, Solomonidis SE, Paul JP: In vitro method for quantifying the effectiveness of the longitudinal arch support mechanism of a foot orthosis. Clin Biomech 1995, 10:245-252.

14. Sharkey NA, Hamel AJ: A dynamic cadaver model of the stance phase of gait: performance characteristics and kinetic validation. Clin Biomech 1998, 13:420-433.

doi:10.1186/1757-1146-7-S1-A38

Cite this article as: Johnson and Ou: Effects of boundary conditions on foot behaviour in the standing position in 3D finite element foot model. Journal of Foot and Ankle Research 2014 7(Suppl 1):A38.

\section{Submit your next manuscript to BioMed Central} and take full advantage of:

- Convenient online submission

- Thorough peer review

- No space constraints or color figure charges

- Immediate publication on acceptance

- Inclusion in PubMed, CAS, Scopus and Google Scholar

- Research which is freely available for redistribution

Submit your manuscript at www.biomedcentral.com/submit 